\title{
REMUNERAC̄̃̃ VARIÁVEL INCENTIVA A CRIAÇÃO DE FOLGA ORÇAMENTÁRIA?
}

\author{
VARIABLE COMPENSATION ENCOURAGES THE CREATION OF BUDGETARY SLACK?
}

\author{
Recebido em 23.04.2014. Aprovado em 14.11.2015 \\ Avaliado pelo sistema double blind review \\ DOI: http://dx.doi.org/10.12712/rpca.v9i4.580
}

\section{Ilse Maria Beuren \\ ilse.beuren@gmail.com \\ Universidade Federal de Santa Catarina (UFSC), Florianópolis/SC, BRASIL}

\section{José Ari Verhagem}

jverhagem@hering.com.br

Universidade Regional de Blumenau (FURB), Blumenau/SC, BRASIL

\begin{abstract}
Resumo
O estudo verifica em que medida a remuneração variável é um incentivo para os gestores criarem folga no processo orçamentário. A pesquisa foi realizada em empresa que possui remuneração variável atrelada às metas orçamentárias. O questionário foi encaminhado para os 48 gestores, sendo que a amostra constitui-se dos 32 respondentes. $\mathrm{O}$ instrumento de coleta de dados consistiu de um questionário traduzido da pesquisa de Onsi (1973). Para delimitar a existência ou não dos elementos de folga organizacional utilizou-se de estatística descritiva. Em seguida, compararam-se as médias das notas das respostas de dois grupos de respondentes: os com maior e os com menor alcance das metas orçamentárias. Os resultados indicaram que os gestores que tiveram desempenho inferior no alcance das metas são mais propensos a criar folga em seus orçamentos. Assim, conclui-se que a remuneração variável atrelada às metas orçamentárias pode contribuir para a prática de criação de folga no processo orçamentário.
\end{abstract}

Palavras-chave: Folga orçamentária. Remuneração variável. Processo orçamentário.

\begin{abstract}
The study verifies in which extent the variable compensation is an incentive for managers to create slack in the budget process. The research was carried in a company which has compensation variable related to budget targets. The questionnaire was sent to the 48 managers, being the sample consisted of 32 respondents. The data collection instrument consisted of a translated questionnaire of Onsie's (1973) research. To define the existence or not of the elements of organizational slack, it was used descriptive statistics. Subsequently, were compared the mean scores of the responses of two groups of respondents: those with high and low achievement of budget targets. The results indicate that managers who underperformed in the achievement of the goals are more likely to create slacks in their budgets. Thus, it is concluded that the variable compensation related to the budget targets may contribute to the practice of creating slacks in the budget process.
\end{abstract}

Keywords: Budget slack. Variable compensation. Budget process. 


\section{Introdução}

O alinhamento das pessoas, que compõem a organização, com a estratégia estabelecida é fundamental para que elas desempenhem atividades condizentes com os objetivos organizacionais. Neste sentido, as empresas precisam investir em processos de gestão que motivem as pessoas no trabalho e as direcionem para o atendimento dos aspectos que são importantes à organização. Os sistemas de remuneração podem ser utilizados com vistas ao cumprimento desses objetivos. Corrêa (1999, p. 33) defende que "a motivação no trabalho é fundamental para que as pessoas passem a exercer suas potencialidades a favor da empresa".

Há diversas formas de compor o sistema de remuneração das empresas, uma delas é a participação nos resultados. Esta consiste em um dos tipos de remuneração variável empregado pelas empresas no sistema de recompensas de seus empregados. A remuneração variável, juntamente com a remuneração funcional (fixa) e de outras formas de remuneração, formam os sistemas de remuneração da organização (MACHADO; BEUREN, 2014).

A participação no resultado tem o intuito de recompensar os esforços individuais e coletivos pela contribuição aos resultados globais da empresa. Geralmente, as metas individuais e corporativas estão atreladas ao orçamento da empresa. O orçamento é para as empresas um dos principais instrumentos de gestão. Segundo Frezatti (2006, p. 44), “o orçamento é um dos pilares da gestão e uma das ferramentas fundamentais para que o accountability, a obrigação dos gestores de prestar contas de suas atividades, possa ser encontrado".

Espejo (2008, p. 73) destaca que, concomitantemente com "duas funções organizacionais essenciais para o gestor, o planejamento e o controle, emerge o orçamento como artefato contábil, que possibilita o direcionamento dos objetivos de longo prazo em um período de curto prazo, revelando a missão da empresa nos níveis táticos e operacionais". O processo orçamentário, quando a gestão é participativa, isto é, quando a gestão não ocorre de forma unilateral no sentido de cima para baixo, na estrutura, é construído pelos gestores.

A avaliação dos gestores baseada em metas individuais e coletivas, atreladas ao orçamento, pode gerar interesse oportunista (JENSEN; MURPHY, 1990), propenso à criação de folga no orçamento. A criação de folga no orçamento significa a escolha de um padrão que possa ser facilmente atingido. A inclinação dos gestores para criar folga orçamentária pode comprometer a eficácia do sistema orçamentário. Neste sentido, um sistema de controle gerencial robusto, em que as regras são claras e as distorções orçamentárias são discutidas, pode trazer mais segurança na condução dos negócios. De acordo com Espejo (2008, p. 73), "O alcance do alvo desejado é exposto por meio da comparação dos resultados alcançados e os pretendidos, possibilitados por processos de controle. Contudo, controle e autonomia são conceitos conflitantes e a escolha do modelo de gestão determina a solução ótima entre eles".

Com base no exposto, independente da metodologia ou do sistema de controle orçamentário utilizado nas organizações, uma questão que se apresenta é: As empresas com remuneração variável, em que as metas estão relacionadas ao orçamento, possuem maior propensão para criar folga no processo orçamentário? Esta questão motivou a presente pesquisa, que tem como objetivo verificar em que medida a remuneração variável é um incentivo para os gestores criarem folga no processo orçamentário.

A pesquisa justifica-se, tanto sob o ponto de vista teórico quanto prático, pela contribuição que se busca dar ao desenvolvimento e à ampliação da investigação sobre o tema. Pretende-se avançar nos estudos sobre folga organizacional e contribuir com pesquisas anteriores que foram realizadas em âmbito internacional e nacional, considerando diferentes ambientes e perspectivas sobre a folga orçamentária.

Fleck e Sender (2005) examinaram a folga organizacional em dois bancos brasileiros: Banco do Brasil e Banco Itaú. Por meio de análise qualitativa, procuraram evidências da ocorrência de folga na recompensa de stakeholders e de sua aderência à estratégia declarada nas instituições investigadas. Os resultados do estudo mostraram que o Banco Itaú recompensa com folga funcionários e gerentes no quesito remuneração, e acionistas com ganhos de capital. No Banco do Brasil, por sua vez, a comunidade e o governo são recompensados com folga, embora tais ações não sejam aderentes à estratégia declarada.

Indjejikian e Matejka (2006) investigaram os determinantes da folga organizacional em uma amostra de 104 unidades de negócios de grandes empresas 
descentralizadas dos Estados Unidos. Para verificar como os sistemas de contabilidade gerencial afetam a folga, os autores mediram a folga organizacional de acordo com as metas de desempenho dos gestores das unidades de negócios. Concluíram que a assimetria de informação entre os controllers da sede da empresa e das unidades de negócios está positivamente associado com a folga organizacional. Verificaram ainda que a folga é maior quando os controllers das unidades de negócios focalizam mais suas responsabilidades de suporte de apoio local do que suas responsabilidades de controle global da organização.

Junqueira, Oyadomari e Moraes (2010) analisaram a adequação do construto teórico de reservas orçamentárias previsto na literatura, empregando, para tanto, uma abordagem epistemológica e de análise bibliográfica. Os autores selecionaram e examinaram os principais estudos empíricos sobre reservas orçamentárias ou folga orçamentária, com vistas em identificar a definição de folga orçamentária, a metodologia e seus principais resultados. $\mathrm{Na}$ análise realizada identificaram as principais causas das reservas orçamentárias e como se pode atenuá-las. Constataram que as reservas são influenciadas pelo estilo do sistema orçamentário. Quando o orçamento é a base da avaliação de desempenho, há uma tendência de aumentar a reserva. Observaram ainda que as reservas aumentam quando o sistema orçamentário é rígido. Por fim, constataram que apesar de alguns avanços, os estudos ainda não são conclusivos quanto às características das organizações que apresentam maior propensão para a constituição de reservas, e dos instrumentos necessários para evitá-la.

Oliveira, Lavarda e Paton (2010) identificaram potenciais fatores culturais favoráveis à criação da reserva orçamentária nas organizações, associados ao ciclo de vida organizacional. A partir das respostas dos gestores dos departamentos que apresentaram folga orçamentária, os autores constataram que há perfis destoantes dos demais respondentes, demonstrando menor predisposição à obediência aos valores e orientação ética. Com base nos resultados da pesquisa, concluíram que os valores e a orientação ética são potencialmente fatores determinantes da existência de folga orçamentária nas empresas.

Neste estudo busca-se investigar em que medida a remuneração variável é um incentivo para os gestores criarem folga no processo orçamentário em uma empresa que tem sua política salarial atrelada à remuneração variável e algumas métricas de desempenho são lastreadas no orçamento. Os resultados da pesquisa de Onsi (1973) indicaram que as motivações para criar folga orçamentária decorrem do interesse dos gestores de apresentar desempenho superior em relação ao previsto no orçamento. Assim, o pressuposto desta pesquisa é que a empresa que tem na composição de sua política salarial componentes de remuneração variável atrelados às metas orçamentárias tende a apresentar folga no orçamento.

\section{Folga organizacional}

Nos estudos sobre folga organizacional não há consenso para uma definição única do assunto e nem mesmo sobre a sua influência efetiva nas organizações. Tais constatações podem ser observadas em Quintas e Beuren (2011), que analisaram as abordagens sobre folga organizacional no contexto das pesquisas publicadas em periódicos científicos internacionais. $\mathrm{Na}$ pesquisa realizada, considerando publicações em âmbito internacional, tendo como referência o termo folga organizacional, constataram que os estudos sobre folga organizacional são amplos e complexos.

Quintas e Beuren (2011) advertem que as pesquisas sobre folga organizacional apresentam conceitos diversos e evolutivos e as abordagens sobre inovação e estratégia são pontos-chaves para as pesquisas relacionadas ao tema, uma vez que foram as mais encontradas na literatura. Entretanto, a mensuração desses tipos de folga de recursos ainda são obscuros nas pesquisas desenvolvidas. Em relação às disciplinas das ciências sociais aplicadas que abordaram o tema folga organizacional, observaram predominância na área da administração (inovação, tecnologia e desempenho). As autoras salientam, no entanto, que pesquisas sobre definições de folga organizacional e de suas relações com aspectos do ambiente organizacional estão evoluindo e sinalizam discussões mais amplas.

Cyert e March (1963) explicam que a folga organizacional é o excesso de recursos disponíveis para a empresa acima do necessário para atender as suas necessidades imediatas. Conforme o autor, trata-se de uma disparidade entre os recursos disponíveis para a organização e os pagamentos necessários para manter a coalizão. Ou seja, a folga representa a diferença entre os recursos existentes e a demanda efetiva. 
Sharfman et al. (1988) definem folga como recursos em excesso, potencialmente recuperáveis, que uma organização necessita para manter suas operações normais. Bormiley (1991) amplia este conceito, ao aduzir que folga organizacional é o excesso de recursos que uma organização pode utilizar para aliviar as diferenças entre mudanças no ambiente em que opera e a necessidade de respostas organizacionais.

Tang e Peng (2003) explicam que a folga pode ser utilizada como proteção à empresa diante de turbulências no ambiente. Verifica-se, portanto, que a folga organizacional está relacionada ao excesso de recursos além do necessário. Esses recursos referemse ao excesso de empregados, capacidade não utilizada ou ociosa e despesas de capital desnecessárias (NOHRIA; GULATI, 1997; LIMA, 2008).

Bourgeois (1981) comenta que a folga possibilita a criação e incentiva a organização a competir no seu ambiente de forma mais ousada. Assim, a organização pode ser mais inclinada para se aventurar em territórios desconhecidos ou não testados e incorrer em maiores riscos. Em uma linha similar, Cyert e March (1963) já destacava que a folga possibilita que as organizações façam experiências de forma mais segura com novas estratégias e projetos inovadores, que podem não ser aprovados em um ambiente com recursos limitados.

Facó (2009) expõe que a literatura explicita que a folga organizacional pode facilitar a adaptação, a inovação, a criatividade e a tomada de risco de uma organização, provendo os recursos necessários para essas posturas. A folga ainda permite absorver falhas, explorar novas ideias, além de fazer frente às necessidades atuais e suportar custos de desenvolvimento e implementação de inovações. Segundo Facó (2009, p. 68), “o tema folga organizacional, pode ser visto sob um prisma que, ao mesmo tempo em que promove um incentivo para oportunidades de inovação, também é uma forma de desperdício e gastos que afetam negativamente resultados de desempenho da empresa".

Sender (2004) agrupou os recursos que podem configurar folga em: humanos, físicos e financeiros. Nos recursos humanos, a folga está no excesso de pessoas trabalhando na organização, além da sua necessidade, ou até mesmo, com horas de folga. Os recursos físicos, referem-se à capacidade das máquinas, existência de matérias primas ou outros recursos além do mínimo necessário para a realização das atividades. Já a folga de recursos financeiros, ocorre quando há salários mais altos do que o necessário, preços mais baixos do que o necessário, dividendos mais altos do que o necessário, capital não utilizado.

Outro aspecto abordado da folga na literatura é quanto aos seus tipos. Os autores têm apresentado diferentes classificações para a folga organizacional, porém, com características similares entre os tipos. A primeira classificação foi apresentada por Bourgeois e Singh (1983), que é a tipologia mais abordada na literatura, na qual classificaram a folga organizacional em disponível, recuperável e potencial.

Folga disponível, refere-se aos recursos disponíveis e que ainda não estão comprometidos em alocações específicas, normalmente associadas ao excesso de liquidez (SENDER, 2004; LIMA, 2008). Folga recuperável, representa os recursos que já foram absorvidos pela atividade operacional, mas que podem ser recuperados pela redução ou reavaliação de algumas despesas, por exemplo o excesso de despesas gerais, redução de custos elevados (SENDER, 2004). Folga potencial, representa a habilidade de a empresa obter recursos extras do ambiente, como habilidade de aumentar o capital, levantando um empréstimo adicional ou colocando ações no mercado (BOURGEOIS; SINGH, 1983; SENDER, 2004; LIMA, 2008).

Outro tipo de folga abordada na literatura é a folga orçamentária. Neste tipo de folga, considera-se que os gestores usam o orçamento como instrumento para conseguir folga orçamentária. Ou seja, há superestimação dos valores de despesas fixadas e/ ou subavaliação dos valores de receitas estimadas no planejamento orçamentário. Antes da exposição deste assunto, faz-se na sequência uma breve explanação sobre processo orçamentário.

\section{Processo orçamentário}

O orçamento é um instrumento de grande valia para as organizações, sendo considerado o principal artefato do sistema de controle gerencial de quase todas as entidades (HANSEN; OTLEY; VAN DER STEDE, 2003; FREZATTI et al., 2010). O orçamento estabelece um compromisso entre os gestores e a estratégia deliberada pelas organizações (FREZATTI et al., 2010).

O orçamento, no Brasil, conforme Leite et al. (2008), teve sua aplicação primeiramente na administração 
pública, com a criação do Erário Régio e do Conselho da Fazenda, em 1808, quando da vinda de D. João VI. Segundo Lunkes (2003), somente a partir de 1940 é que ele passou a ser foco de estudos no país, e em 1970 é que ocorreu seu apogeu, época em que as empresas passaram a adotá-lo com mais intensidade.

Anthony e Govindarajan (1998) apresentam algumas características do orçamento, sendo elas:

a) estima o potencial de lucro;

b) é apresentado em termos monetários, mesmo que as cifras possam ser fundamentadas em valores não monetários, por exemplo, unidades a serem vendidas e/ou produzidas;

c) geralmente compreende o período de um ano;

d) é um compromisso gerencial, no qual os executivos se responsabilizam pelo cumprimento dos objetivos definidos no orçamento;

e) a proposta orçamentária é aprovada por autoridade mais alta do que os responsáveis pela execução do orçamento;

f) uma vez aprovado, o orçamento só pode ser alterado sob condições especiais;

g) há acompanhamento do desempenho financeiro real, comparando-o com o orçamento e as variações são analisadas e explicadas.

A partir da revisão da literatura sobre orçamento, Frezatti et al. (2010) destacaram alguns benefícios advindos do mesmo, sendo eles: define metas e objetivos e serve como benchmarks para futura avaliação de desempenho; provê uma forma de alocar recursos entre os departamentos e as áreas; coordena as atividades por meio da integração dos planos das várias áreas e auxilia para que estes estejam na mesma direção; provê uma forma de comunicação gerencial acerca dos planos; força os gerentes a pensar sobre ações para o futuro, evitando que estes, na ausência do orçamento, gastem esforços em ações do cotidiano.

Mussa, Rêgo e Securato (2010) identificaram também algumas críticas ao processo orçamentário, e citaram 12 delas conforme apontadas por Neely, Sutcliff e Heyns
(2001): consomem muito tempo para sua elaboração; restringem a responsabilidade e são restritos à mudança; raramente são focados estrategicamente e muitas vezes contraditórios; adicionam pouco valor, dado o limitado tempo de consecução do orçamento; concentram-se em redução de custos e não no acréscimo de valor; transmitem apenas o comando e controle vertical; não ilustram a estrutura emergente de interligações que as organizações estão adotando; encorajam o jogo e a adoção de comportamentos disfuncionais; são desenvolvidos e atualizados com pouca frequência, basicamente de forma anual; são fundamentados em premissas sem suporte real; reforçam as barreiras interdepartamentais em detrimento do conhecimento compartilhado; e desmotivam as pessoas.

Um destes comportamentos disfuncionais expostos na literatura é a folga orçamentária ou reservas orçamentárias, conforme abordado por alguns autores (LAVARDA; FANK, 2014). A folga orçamentária ocorre quando há uma superestimação de custos/ despesas ou subestimação de receitas, fazendo com que os objetivos orçamentários sejam fáceis de serem atingidos (BOURGEOIS; SINGH, 1983). A folga orçamentária se reflete no desempenho econômicofinanceiro das empresas, conforme observado por Beuren, Starosky Filho e Krespi (2014) nas empresas listadas na BM\&FBovespa, no período analisado.

Onsi (1973) pesquisou empiricamente as conexões entre o sistema orçamentário e a propensão para criar folga orçamentária. O autor realizou entrevista com 32 gerentes de cinco multinacionais norte-americanas com estrutura divisional. Constatou que $80 \%$ dos gerentes que entrevistou afirmaram introduzir folga no orçamento, principalmente quando o orçamento é a base da avaliação de desempenho. Concluiu que a folga orçamentária é influenciada pelo estilo do sistema orçamentário. E que a participação no processo de elaboração do orçamento pode reduzir a necessidade de se criar folga por parte dos gerentes.

A propensão em constituir folga pode decorrer da ênfase no orçamento em termos de evidenciação de desempenho, do modo de condução do orçamento participativo, da assimetria informacional e da incerteza quanto às informações disponíveis para o planejamento (DAVILA; WOUTERS, 2005). Para reduzir a folga orçamentária, os autores recomendam que deve existir feedback do desempenho, maior 
participação no orçamento, implantação de medidas de controle de custos, entre outras. Maior participação no processo orçamentário é apontada por Beuren e Silva (2014) como uma das formas de valorização das pessoas.

Observa-se do exposto que uma das causas da folga orçamentária é quando o orçamento é a base de avaliação dos executivos, em que a remuneração, bônus ou gratificação estão atrelados ao cumprimento dos objetivos orçamentários. Ou seja, os executivos são remunerados por meio do cumprimento do orçamento. Assim, o próximo tópico faz uma incursão teórica na remuneração variável.

\section{Remuneração variável}

A lógica da geração de valor ao acionista, que pode ser entendida como uma evolução da concepção financeira da empresa (FISCHER, 2002), vem ganhando força nas últimas décadas, em virtude de uma série de fatores, sendo o principal deles a concentração das ações nas mãos de investidores institucionais. Soares (2006) explica que estes investidores tendem a exercer enorme pressão sobre os gestores em busca de maior retorno sobre o investimento realizado nos papéis destas empresas. O autor explica que este cenário influencia de modo geral todas as práticas de gestão das organizações que se inserem neste contexto.

Wood Junior e Picarelli Filho (1999) descrevem que a abordagem estratégica de remunerar surgiu em um contexto de mudanças das empresas, em que as pesadas estruturas hierárquicas do século $\mathrm{XX}$ deram lugar às estruturas mais enxutas e as transformações na forma de gerir exigiram soluções rápidas e criativas. Esses autores aduzem que a abordagem estratégica de remunerar reflete, de certo modo, a realidade das empresas que atuam no mundo globalizado e competitivo.

Soares (2006, p. 11-12) afirma que, ao aprofundar-se na literatura existente sobre o tema, percebe-se claramente que "o principal elo entre a lógica da geração de valor ao acionista e a gestão de pessoas é a remuneração variável". O pressuposto é que "os funcionários de uma empresa irão se comprometer com a 'causa' da geração de valor ao acionista desde que parte deste valor gerado seja com eles compartilhado". O autor ressalta que "este comprometimento será gerado se os funcionários perceberem a possibilidade de também obterem benefícios financeiros com a criação de valor ao acionista".

Krauter e Sousa (2013) reforçam que a remuneração é um dos sistemas mais relevantes e complexos na administração de recursos humanos, porque busca alinhar os colaboradores às metas das empresas, por meio de incentivos. Um dos tipos de remuneração que vem se destacando nos últimos tempos é a remuneração variável, para além da remuneração fixa. Machado e Beuren (2014) explicam que há diversos mecanismos pelos quais a política de remuneração pode oferecer um valor maior de incentivos, incluindo bônus anuais, acréscimos salariais baseados em desempenho, benefícios diversos (seguro de vida, plano de aposentadoria complementar, entre outros).

No entanto, para que sejam implementadas as práticas de remuneração variável, é necessário haver um sistema de gestão de desempenho, por meio do qual sejam estipuladas metas, avaliados os resultados alcançados e estimulada continuamente a melhoria do desempenho. Estas metas podem estar atreladas ao sistema de orçamento. Marquart, Lunkes e Rosa (2012) explicam que a remuneração variável é uma maneira de recompensa que utiliza critérios préestabelecidos para determinar o montante a ser pago aos empregados no final de um período. Os autores comentam que em geral os critérios mais utilizados são: produtividade, resultados e lucros.

A utilização do orçamento como delineador de metas para a remuneração variável também é reforçada por Krauter e Sousa (2013), quando mencionam que a remuneração variável é o montante recebido em dinheiro em razão do alcance de determinadas metas, que, muitas vezes, são fixadas aos executivos na elaboração do orçamento. Porém, a sistemática de remuneração variável não é tão perfeita quanto parece. Odelius e Santos (2008) expõem que um sistema de remuneração eficaz precisa caracterizarse pela flexibilidade, dinâmica e alinhamento com os objetivos estratégicos e o negócio da organização.

\section{Metodologia da pesquisa}

O estudo foi desenvolvido por meio de pesquisa descritiva, com abordagem quantitativa, realizada com base em um estudo de caso. Conforme Gil (1999, 
p. 46), "a pesquisa descritiva tem como objetivo primordial descrever as características de determinada população ou fenômeno ou, então, o estabelecimento de relações entre variáveis. Também se caracteriza pela utilização de técnicas padronizadas de coleta de dados".

Em consonância com o problema da pesquisa, privilegiou-se o uso da estratégia da abordagem quantitativa. De acordo com Richardson (1999), a pesquisa quantitativa caracteriza-se pelo emprego de ferramentais estatísticos, tanto na coleta quanto no tratamento dos dados, abrangendo desde técnicas simples, como percentuais, média, desvio-padrão, até mais complexas, como coeficiente de correlação, análise de regressão, entre outras.

O estudo de caso possibilita estudar de forma mais aprofundada uma realidade específica e seus resultados poderão contribuir para estudos futuros (GIL, 1999). Martins e Theóphilo (2007) explicam que o estudo de caso refere-se à uma investigação empírica que pesquisa fenômenos dentro do seu contexto real, onde o pesquisador não tem controle sobre eventos e variáveis, procurando apreender a totalidade de uma situação e, criativamente, descrever, compreender e interpretar a complexidade de um caso concreto.

Segundo Yin (2004), há vários fundamentos que justificam a escolha do estudo de caso em uma única empresa. Dentre eles, quando é um caso revelador, em que o pesquisador tem a oportunidade de estudar e analisar um fenômeno pouco acessível à investigação científica. O estudo de caso foi realizado em uma grande empresa do Sul do país. A empresa possui mais de 6.000 funcionários, atua no mercado há mais de um século e se destaca pelas estratégias adotadas para tornar-se cada vez mais competitiva e lucrativa. A escolha desta empresa para a investigação deve-se ao fato da mesma possuir um plano de remuneração variável abrangente, em que a composição da remuneração de seus empregados na participação dos resultados está atrelada às metas corporativas e individuais.

Conforme relatado nas Demonstrações Financeiras Padronizadas (DFP) de 2009, a companhia "concede a todos os empregados, um bônus relacionado aos planos de participação nos resultados, os quais estão vinculados ao alcance de objetivos específicos, baseado no cumprimento de metas individuais e corporativas, estabelecidos e acordados no início de cada ano".
Neste mesmo relatório, a empresa declara que, para o ano de 2009, o valor referente ao bônus relativo à participação nos resultados foi de $\mathrm{R} \$ 17,8$ milhões, o que representa $2,5 \%$ da receita líquida do ano.

A coleta de dados foi realizada em dois momentos e por instrumentos diferentes. Primeiramente foi realizada uma entrevista semi-estruturada com o Diretor Administrativo da empresa. Segundo Triviños (1987), a entrevista semiestruturada utiliza-se inicialmente de certos questionamentos básicos, apoiado em teorias e hipóteses que interessam à pesquisa, e que, em seguida, adiciona-se outros questionamentos, frutos do desenrolar da entrevista. Este instrumento foi utilizado para levantar as principais características do plano de participação nos resultados, além do vínculo que as metas corporativas e individuais têm com o orçamento.

Ainda nesta entrevista foi levantado o nome e o endereço eletrônico de todos os executivos que participam do processo orçamentário da empresa, para dar suporte à segunda etapa de coleta de dados. Os executivos que participam do processo orçamentário ocupam cargos de gerência ou de diretoria, num total de 48 gestores, representados pelas áreas administrativa, financeira, comercial, marketing, industrial e técnica. Por sua vez, a amostra compõe-se dos 32 respondentes, representando 67\% da população.

$\mathrm{Na}$ segunda etapa foi utilizado o levantamento. De acordo com Gil (1999, p. 73), levantamentos "se caracterizam pela interrogação direta das pessoas cujo comportamento se deseja conhecer". O autor explica que neste tipo de pesquisa "procede-se à solicitação de informações a um grupo significativo de pessoas acerca do problema estudado para, em seguida, mediante análise quantitativa, obter as conclusões correspondentes aos dados coletados". Para esta coleta de dados foi utilizado o questionário traduzido da pesquisa realizada por Onsi (1973), composto de 42 questões fechadas, envolvendo escala Likert de cinco pontos, que varia entre "concordo totalmente" e "discordo totalmente".

Este questionário possibilitou analisar fatores de 14 dimensões da prática da gestão do orçamento, focalizando a folga orçamentária, conforme demonstrado no Quadro 1. 
Quadro 1: Dimensões da prática da gestão do orçamento

\begin{tabular}{|c|c|c|}
\hline Dimensões & Características & $\begin{array}{l}\mathbf{N}^{\circ} \text { de } \\
\text { perguntas }\end{array}$ \\
\hline $\begin{array}{l}\text { 1) Folga do responsável } \\
\text { da área na elaboração do } \\
\text { orçamento }\end{array}$ & $\begin{array}{l}\text { Foi descrita pelas variáveis, indicando a atitude de um gestor para a folga. Esta } \\
\text { dimensão é a variável dependente, no sentido de um modelo de regressão, e } \\
\text { as outras } 13 \text { dimensões são as variáveis independentes. }\end{array}$ & 4 \\
\hline $\begin{array}{l}\text { 2) Manipulação do } \\
\text { orçamento }\end{array}$ & $\begin{array}{l}\text { Ela foi descrita pelas variáveis que indicam como um gestor constrói e usa } \\
\text { a folga. }\end{array}$ & 2 \\
\hline $\begin{array}{l}\text { 3) Institucionalização de } \\
\text { folgas }\end{array}$ & $\begin{array}{l}\text { Ela foi descrita pelas variáveis que fazem um gestor ser menos inclinado } \\
\text { a reduzir sua folga. O gestor pode considerar uma parcela de folga a ser } \\
\text { institucionalizada e, portanto, irredutível. }\end{array}$ & 3 \\
\hline 4) Detecção de folgas & $\begin{array}{l}\text { Foi descrita pelas variáveis que indicam a capacidade para detectar folga com } \\
\text { base na quantidade de informação que o gestor recebe. }\end{array}$ & 3 \\
\hline $\begin{array}{l}\text { 5) Atitude em relação ao } \\
\text { sistema de controle da alta } \\
\text { administração }\end{array}$ & $\begin{array}{l}\text { Foi descrita pelas variáveis que indicam uma filosofia autoritária pelo superior } \\
\text { hierárquico, atribuída aos subordinados em relação ao orçamento. }\end{array}$ & 4 \\
\hline $\begin{array}{l}\text { 6) Atitude em relação aos } \\
\text { subordinados } \\
\text { 7) Pressão } \\
\text { 8) Autonomia orçamentária } \\
\text { 9) Participação } \\
\text { no orçamento } \\
\text { 10) Práticas de fiscalização } \\
\text { do orçamento }\end{array}$ & $\begin{array}{l}\text { As cinco dimensões foram, em sequência: atitude dos subordinados, fontes de } \\
\text { pressão, autonomia orçamentária, participação do orçamento, e fiscalização } \\
\text { do uso dos orçamentos. Cada dimensão foi descrita pelas variáveis indicando } \\
\text { seus atributos relevantes. As cinco dimensões representam a atitude sobre o } \\
\text { sistema de controle. }\end{array}$ & 16 \\
\hline $\begin{array}{l}\text { 11) Atitude relativa } \\
\text { aos critérios } \\
\text { 12) Atitude relativa à } \\
\text { relevância de atingir } \\
\text { o orçamento na } \\
\text { avaliação da performance } \\
\text { 13) Propósito do orçamento }\end{array}$ & $\begin{array}{l}\text { As três dimensões foram, em sequência: atitude em relação ao nível dos } \\
\text { padrões, atitude em relação à relevância do orçamento, realização de uma } \\
\text { avaliação de desempenho, e atitude do gestor (positiva ou negativa) para } \\
\text { o sistema orçamentário, em geral, como uma ferramenta de gestão. Cada } \\
\text { dimensão foi descrita pelas variáveis relevantes, indicando seus atributos. As } \\
\text { três dimensões representam as atitudes a respeito do orçamento. }\end{array}$ & 7 \\
\hline $\begin{array}{l}\text { 14) Importância do } \\
\text { orçamento }\end{array}$ & $\begin{array}{l}\text { Ele foi descrito por variáveis, que indicam a atitude do gestor em relação à } \\
\text { relevância dos padrões para a operação do seu departamento. }\end{array}$ & 3 \\
\hline
\end{tabular}

Fonte: Onsi (1973).

No que concerne à análise dos dados, primeiramente foram descritos os resultados da entrevista semi-estruturada com o Diretor Administrativo da empresa investigada. Destacaram-se as principais características do plano de participação nos resultados, além do vínculo que as metas corporativas e individuais têm com o orçamento da empresa.

Em seguida, os dados coletados no levantamento foram tabulados em planilha do Microsoft Excel e importados para o software estatístico SPSS. Inicialmente fez-se a análise por meio de estatística descritiva, com o cálculo de frequência, delimitando-se a existência ou não dos elementos de folga orçamentária objeto de estudo. Quanto maior a dispersão das respostas dentro de cada elemento, menor é a percepção da existência de folga. Em seguida, compararam-se as médias das notas das respostas dos grupos de respondentes com maior e menor alcance das metas do orçamento, utilizando o Teste T-Student (HAIR JR, 2005).

\section{Análise dos resultados}

$\mathrm{Na}$ análise dos resultados, inicialmente apresentou-se o perfil dos respondentes. Em seguida, evidenciara-se as principais características do plano de participação nos resultados, e sua ligação com o processo orçamentário da empresa investigada. Após, procedeu-se à análise descritiva dos elementos de folga orçamentária e das médias 
das notas atribuídas às questões pelos respondentes, para comparar os grupos de respondentes com maior e menor alcance das metas orçamentárias.

\section{Perfil dos respondentes}

No que concerne ao perfil dos respondentes, investigou-se a idade e o gênero dos respondentes, bem como seu grau de escolaridade, área de atuação e tempo que trabalha na empresa. Os dados tabulados são apresentados na Tabela 1.

Tabela 1: Perfil dos respondentes

\begin{tabular}{l|c|c}
\hline Idade & Respondentes & $\mathbf{\%}$ \\
\hline Menos de 29 anos & 0 & 0,00 \\
\hline De 30 a 39 anos & 13 & 40,63 \\
\hline De 40 a 49 anos & 12 & 37,50 \\
\hline Mais de 50 anos & 7 & 21,88 \\
\hline Total & $\mathbf{3 2}$ & $\mathbf{1 0 0 , 0 0}$ \\
\hline Gênero & 25 & 78,13 \\
\hline Masculino & 7 & 21,88 \\
\hline Feminino & $\mathbf{3 2}$ & $\mathbf{1 0 0 , 0 0}$ \\
\hline Total & & \\
\hline Escolaridade & 5 & 15,63 \\
\hline Graduação & 22 & 68,75 \\
\hline $\begin{array}{l}\text { Pós graduação Latu } \\
\text { Sensu }\end{array}$ & 5 & 15,63 \\
\hline $\begin{array}{l}\text { Pós graduação Strictu } \\
\text { Sensu }\end{array}$ & $\mathbf{3 2}$ & $\mathbf{1 0 0 , 0 0}$ \\
\hline Total & & \\
\hline Área de atuação & 9 & 28,13 \\
\hline Administrativa/ & 12 & 37,50 \\
\hline Financeira & 11 & 34,38 \\
\hline Comercial/Marketing & $\mathbf{3 2}$ & $\mathbf{1 0 0 , 0 0}$ \\
\hline Produtiva/Técnica & & \\
\hline Total & $\mathbf{3 2}$ & 12,50 \\
\hline Tempo de atuação & & 25,00 \\
\hline Menos de 05 anos & & 34,38 \\
\hline De 06 a 14 anos & $\mathbf{1 0 0 , 0 0}$ \\
\hline De 15 a 25 anos & & \\
\hline Mais de 25 anos & 9 & \\
\hline Total & & \\
\hline
\end{tabular}

Com relação ao perfil dos respondentes, no quesito idade observa-se que 59,38\% possuem mais de 40 anos. Do total dos respondentes, $78,13 \%$ são do gênero masculino e 68,75\% são pós-graduados em nível de especialização. Quanto à área de atuação, os respondentes são bastante heterogêneos, com uma leve predominância da área comercial/marketing. No que concerne ao tempo de atuação na empresa, observa que $62,51 \%$ possuem mais de 15 anos de empresa. Este perfil permite inferir que os respondentes apresentam condições de contribuir para a indagação descrita na questão da pesquisa.

\section{Plano de participação nos resultados e sua ligação com o processo orçamentário}

Os dados levantados na entrevista semiestruturada, relativos às principais características do plano de participação nos resultados, acrescidos de dados extraídos da pesquisa realizada em documentos fornecidos pela empresa, estão descrito a seguir.

Um dos componentes da remuneração estratégica da empresa é a participação nos resultados da empresa, plano que engloba todos os seus empregados. O plano de participação nos resultados possui duas modalidades: a) plano de participação nos resultados para os executivos; b) plano de remuneração que abarca os demais empregados. O plano de remuneração para os executivos possui salários bases diferenciados pelo cargo que cada executivo ocupa e pela característica da função. As características de cada função se diferenciam em função de apoio e função de linha.

Todos os executivos são avaliados por metas corporativas e individuais. Uma percentagem da composição do bônus é mensurada pela meta corporativa, que nos últimos anos tem sido o Earnings Before Interest, Taxes, Depreciation and Amortization (EBITDA). Este indicador de desempenho é derivado do alcance das metas do orçamento. As metas individuais são específicas de cada área, na maioria também são atreladas ao orçamento. Alguns exemplos de metas atreladas ao orçamento são: total de vendas; margem de contribuição; custo fixo indireto; despesas operacionais; investimento de capital. Alguns exemplos de metas individuais não atreladas ao orçamento são: índices de qualidade; índice de inadimplência; prazo de entrega; projetos específicos.

O plano de remuneração para os demais empregados possui a mesma quantidade de salários base para todos os participantes, além de metas corporativas, departamentais e individuais. A meta corporativa utiliza-se do Lucro Operacional Líquido como 
indicador e que tem seu direcionador estabelecido pelo orçamento. Para as metas departamentais, a grande maioria dos departamentos utilizou-se do orçamento de despesa do departamento como direcionador. As metas individuais geralmente baseiam-se no absenteísmo como direcionador. Depreende-se que a remuneração variável adotada pela empresa está em linha com o preconizado por Marquart, Lunkes e Rosa (2012), de que essa maneira de recompensa, em geral, baseia-se em critérios de produtividade, resultados e lucros.

As duas modalidades do plano de participação nos resultados da empresa possibilitam aos empregados atingir metas que vão de 0\% a 200\% de seus salários bases. Desta forma, a empresa incentiva os empregados não somente a atingir suas metas, mas superá-las em níveis representativos que conduzam os participantes a buscar os $200 \%$ da meta. Estes resultados da pesquisa na empresa objeto de estudo coadunam com o observado por Krauter e Sousa (2013), de que a remuneração variável decorre do alcance de determinadas metas e que, muitas vezes, são pautadas na realização do orçamento.

\subsection{Estatística descritiva dos elementos de folga organizacional}

A Tabela 2 apresenta as perguntas que possibilitaram analisar a propensão dos gestores a criar folga organizacional na gestão do orçamento. Os dados foram tabulados em planilha eletrônica e a média $(\overline{\mathbf{X}})$ e o desvio padrão $(\square)$ foram obtidas com o software estatístico SPSS. Os respondentes foram solicitados a assinalar suas respostas em uma escala Likert de cinco pontos, representadas por Discordo Totalmente (DT), Discordo Parcialmente (DP), Não tenho Opinião (NO), Concordo Parcialmente (CP) ou Concordo Totalmente (CT).

Tabela 2: Estatística descritiva dos elementos de folga organizacional

\begin{tabular}{|c|c|c|c|c|c|c|c|c|}
\hline QUESTÕES & DT & DP & NO & $\mathrm{CP}$ & CT & $\mathbf{T}$ & & $\sigma$ \\
\hline \multicolumn{9}{|l|}{ Folga do responsável da área na elaboração do orçamento } \\
\hline $\begin{array}{l}\text { 26) Para se proteger, o responsável da área de negócios apresenta um } \\
\text { orçamento que pode ser facilmente alcançado }\end{array}$ & 11 & 13 & 1 & 4 & 3 & 32 & 2,22 & 1,31 \\
\hline $\begin{array}{l}\text { 27) O responsável pela área de negócios estabelece dois níveis de } \\
\text { critérios: um entre ele mesmo e seu superior, e o outro critério entre ele } \\
\text { e seu subordinado, para ser cauteloso }\end{array}$ & 12 & 3 & 3 & 13 & 1 & 32 & 2,63 & 1,43 \\
\hline $\begin{array}{l}\text { 30) Folgas no planejamento orçamentário são boas para fazer coisas que } \\
\text { não podem ser oficialmente aprovadas }\end{array}$ & 15 & 6 & 2 & 6 & 3 & 32 & 2,25 & 1,46 \\
\hline $\begin{array}{l}\text { 41) Em tempos favoráveis o responsável pela área de negócios concorda } \\
\text { com a elaboração de um orçamento cujas metas sejam mais fáceis de } \\
\text { atingir }\end{array}$ & 15 & 8 & 4 & 5 & 0 & 32 & 1,97 & 1,12 \\
\hline \multicolumn{9}{|l|}{ Manipulação do orçamento } \\
\hline $\begin{array}{l}\text { 24) Com alguma habilidade, o responsável pela área de negócios pode } \\
\text { determinar sua performance pessoal, de acordo com seus interesses }\end{array}$ & 4 & 7 & 9 & 11 & 1 & 32 & 2,94 & 1,11 \\
\hline $\begin{array}{l}\text { 29) Os subordinados são informados pelo superior hierárquico da área } \\
\text { sobre a necessidade de atingir as metas orçamentárias }\end{array}$ & 0 & 1 & 0 & 7 & 24 & 32 & 4,69 & 0,64 \\
\hline \multicolumn{9}{|l|}{ Institucionalização de folgas } \\
\hline $\begin{array}{l}\text { 31) Em períodos de crise, a área mais lucrativa em períodos posteriores é } \\
\text { menos propensa a reduzir suas folgas no plano orçamentário que outras } \\
\text { áreas com resultados inferiores }\end{array}$ & 4 & 5 & 10 & 10 & 3 & 32 & 3,09 & 1,17 \\
\hline $\begin{array}{l}\text { 33) O responsável pela área de negócios que está no cargo por um longo } \\
\text { tempo é menos propenso a reduzir folgas orçamentárias por meio de } \\
\text { cortes dos gastos e despesas do que um colega que assumiu outra área } \\
\text { de negócios há pouco tempo }\end{array}$ & 8 & 6 & 4 & 12 & 2 & 32 & 2,81 & 1,35 \\
\hline $\begin{array}{l}\text { 34) O responsável da área de negócios com uma forte personalidade será } \\
\text { menos propenso a reduzir folgas em seu orçamento }\end{array}$ & 6 & 6 & 2 & 13 & 5 & 32 & 3,16 & 1,42 \\
\hline
\end{tabular}




\section{Detecção de folgas}

28) O superior hierárquico tem informações suficientes para saber se há folga no plano orçamentário de seu subordinado

40) O superior hierárquico recebe informações detalhadas sobre as atividades da área de negócios

42) O superior hierárquico tem como saber se há folga no orçamento da área de negócios

\begin{tabular}{|c|c|c|c|c|c|c|c|}
\hline 0 & 1 & 4 & 18 & 9 & 32 & 4,09 & 0,73 \\
\hline 0 & 3 & 2 & 10 & 17 & 32 & 4,28 & 0,96 \\
\hline 0 & 2 & 2 & 15 & 13 & 32 & 4,22 & 0,83 \\
\hline
\end{tabular}

\section{Atitude em relação ao sistema de controle da alta administração}

35) O superior hierárquico avalia a performance da área de negócios baseada somente no atendimento das metas orçamentárias

37) O superior hierárquico repudia o subordinado da área de negócios negligente com seu orçamento

38) O superior hierárquico exerce pressão para que as metas orçamentárias das áreas de negócio aconteçam

39) Se o responsável pela área de negócios falha no atendimento de seu orçamento, o superior hierárquico determina medidas enérgicas

\section{Atitude em relação aos subordinados}

10) Meus subordinados aprendem que obediência e respeito pela autoridade são importantes virtudes

13) Uma ordem clara ao subordinado evita discussões e garante a execução da tarefa

16) Subordinados devem aceitar as decisões dos seus chefes incondicionalmente

17) Se as pessoas falarem menos e trabalharem mais, todos estarão em melhor situação

\section{Pressão}

23) Eu pressiono meus colaboradores para obter resultados

32) O orçamento é elaborado de modo a colocar pressão para aumentar produtividade e controle dos custos

\section{Autonomia orçamentária}

4) O orçamento é elaborado de acordo com meus interesses

20) Meu superior hierárquico aceita meu planejamento orçamentário sem reservas

22) Eu tenho completa autonomia em tomar decisões referentes à elaboração do orçamento da área de negócios

\begin{tabular}{|l|l|l|l|l|l|l|l}
\hline 6 & 13 & 4 & 8 & 1 & 32 & 2,53 & 1,16 \\
\hline 3 & 5 & 5 & 12 & 7 & 32 & 3,47 & 1,27 \\
\hline 0 & 0 & 1 & 10 & 21 & 32 & 4,63 & 0,55 \\
\hline 3 & 5 & 3 & 16 & 5 & 32 & 3,47 & 1,22 \\
\hline
\end{tabular}

\section{Participação no orçamento}

25) Eu recebo metas de meu superior hierárquico para usar como base na elaboração do planejamento orçamentário

2) Eu participo de reuniões gerenciais em que as discrepâncias orçamentárias são discutidas

21) Meu superior hierárquico atende minhas solicitações para melhorar o orçamento

9) Meus interesses são levados em conta tanto quanto possível

\section{Práticas de fiscalização do orçamento}

1) Meu superior hierárquico utiliza os números orçamentários para tomar decisões no que se refere à área de negócios

12) Meu superior hierárquico enfatiza a redução de custos

14) A alta administração avalia comigo o cumprimento do orçamento da área de negócios pela qual sou responsável

\begin{tabular}{|l|l|l|l|l|l|l|l}
6 & 4 & 4 & 12 & 6 & 32 & 3,25 & 1,41 \\
\hline 2 & 5 & 0 & 10 & 15 & 32 & 3,97 & 1,31 \\
\hline 16 & 8 & 1 & 7 & 0 & 32 & 1,97 & 1,20 \\
\hline 9 & 9 & 2 & 11 & 1 & 32 & 2,56 & 1,32 \\
\hline 3 & 1 & 0 & 13 & 15 & 32 & 4,13 & 1,21 \\
\hline 1 & 2 & 1 & 14 & 14 & 32 & 4,19 & 1,00 \\
\hline
\end{tabular}

\section{Atitude relativa aos critérios}

3) Eu prefiro elaborar um orçamento que possa ser atingido

36) Os colegas das outras áreas de negócios preferem elaborar seus orçamentos de forma a ultrapassar o planejado, do que não conseguir atingir as metas

\begin{tabular}{l|l|l|l|l|l|l|l}
13 & 14 & 1 & 2 & 2 & 32 & 1,94 & 1,13 \\
\hline 10 & 12 & 1 & 8 & 1 & 32 & 2,31 & 1,26 \\
\hline 10 & 7 & 1 & 10 & 4 & 32 & 2,72 & 1,51 \\
\hline
\end{tabular}

\begin{tabular}{c|c|c|c|c|c|c|c}
2 & 6 & 1 & 13 & 10 & 32 & 3,72 & 1,28 \\
\hline 6 & 12 & 3 & 9 & 2 & 32 & 2,66 & 1,26 \\
\hline 3 & 7 & 2 & 19 & 1 & 32 & 3,25 & 1,14 \\
\hline 1 & 4 & 2 & 12 & 13 & 32 & 4,00 & 1,14 \\
\hline
\end{tabular}

\begin{tabular}{c|c|c|c|c|c|c|c}
0 & 0 & 1 & 16 & 15 & 32 & 4,44 & 0,56 \\
\hline 0 & 2 & 0 & 9 & 21 & 32 & 4,53 & 0,80 \\
\hline 3 & 5 & 3 & 12 & 9 & 32 & 3,59 & 1,32 \\
\hline
\end{tabular}

\begin{tabular}{|l|l|l|l|l|l|l|l}
0 & 1 & 1 & 8 & 22 & 32 & 4,59 & 0,71 \\
\hline 5 & 8 & 4 & 11 & 4 & 32 & 3,03 & 1,33 \\
\hline
\end{tabular}




\begin{tabular}{|c|c|c|c|c|c|c|c|c|}
\hline \multicolumn{9}{|l|}{$\begin{array}{l}\text { Atitude relativa à relevância de atingir o orçamento para } \\
\text { avaliação }\end{array}$} \\
\hline $\begin{array}{l}\text { 18) Recebo algum tipo de bonificação se atingir os objetivos do plano } \\
\text { orçamentário da minha área de negócios }\end{array}$ & 2 & 0 & 4 & 15 & 11 & 32 & 4,03 & 1,03 \\
\hline $\begin{array}{l}\text { 19) Se eu não realizar os valores orçados, meu superior hierárquico faz } \\
\text { questionamentos }\end{array}$ & 0 & 0 & 1 & 3 & 28 & 32 & 4,84 & 0,45 \\
\hline $\begin{array}{l}\text { 15) Na avaliação do meu superior hierárquico, as habilidades para obter } \\
\text { resultados de seus colaboradores é considerado }\end{array}$ & 0 & 0 & 1 & 8 & 23 & 32 & 4,69 & 0,54 \\
\hline \multicolumn{9}{|l|}{ Propósito do orçamento } \\
\hline $\begin{array}{l}\text { 7) O orçamento é um dos instrumentos essenciais para a minha área de } \\
\text { negócios }\end{array}$ & 0 & 2 & 1 & 8 & 21 & 32 & 4,50 & 0,84 \\
\hline $\begin{array}{l}\text { 11) Eu acredito que tentar realizar o planejado no orçamento é como } \\
\text { um jogo }\end{array}$ & 9 & 4 & 2 & 14 & 3 & 32 & 2,94 & 1,46 \\
\hline \multicolumn{9}{|l|}{ Importância do orçamento } \\
\hline $\begin{array}{l}\text { 5) Os critérios que são estabelecidos na construção do plano orçamentário } \\
\text { influenciam o aumento de produtividade }\end{array}$ & 0 & 3 & 2 & 18 & 9 & 32 & 4,03 & 0,86 \\
\hline $\begin{array}{l}\text { 6) Se fosse possível eu gostaria de trabalhar com mais liberdade, sem me } \\
\text { preocupar excessivamente em realizar o plano orçamentário }\end{array}$ & 10 & 9 & 0 & 10 & 3 & 32 & 2,59 & 1,46 \\
\hline $\begin{array}{l}\text { 8) Se nenhum critério fosse estabelecido pelo meu superior hierárquico, } \\
\text { isso faria com que a performance da minha área de negócios seria melhor } \\
\text { do que a que tenho alcançada. }\end{array}$ & 14 & 12 & 2 & 3 & 1 & 32 & 1,91 & 1,09 \\
\hline
\end{tabular}

Observa-se na Tabela 2, que na dimensão "Folga do responsável da área na elaboração do orçamento", a maioria discorda que o responsável da área elabore o orçamento com folga. Na dimensão "Manipulação do orçamento", a maioria apontou que os subordinados são informados pelo superior hierárquico da área sobre a necessidade de atingir as metas. No que concerne à dimensão "Institucionalização de folgas", os respondentes manifestaram opiniões que ficaram divididas entre as alternativas apresentadas. Com relação à dimensão "Detecção de folgas", a maioria concorda que o superior hierárquico tem como saber se há folga nos orçamentos das áreas, mesmo sendo de diferentes naturezas, humanos, físicos e/ou financeiros (SENDER, 2004).

Na dimensão "Atitude em relação ao sistema de controle da alta administração", os respondentes indicaram que respeitam o sistema de controle. No que diz respeito à dimensão "Atitude em relação aos subordinados", a maioria discorda que os subordinados devem aceitar as decisões dos seus chefes incondicionalmente. Em se tratando da dimensão "Pressão", a maioria concorda que o orçamento é elaborado de modo a colocar pressão para aumentar produtividade e controle dos custos. Essa ênfase no orçamento para avaliar o desempenho pode levar à propensão dos gestores constituir folga orçamentária (DAVILA; WOUTERS, 2005).

Com relação à dimensão "Autonomia no orçamento", a maioria discorda que o orçamento é elaborado de acordo com os seus interesses. No que concerne à dimensão "Participação no orçamento", a maioria concorda que seus interesses são levados em conta tanto quanto possível. Davila e Wouters (2005) já advertiam que a propensão para o gestor constituir folga pode ter como uma das causas a condução do orçamento participativo. Na dimensão "Práticas de fiscalização do orçamento", a maioria concorda totalmente que o superior hierárquico enfatiza a redução de custo, pois a folga orçamentária se reflete no desempenho econômico-financeiro das empresas (BEUREN; STAROSKY FILHO; KRESPI, 2014).

A média da dimensão "Atitude relativa a critérios" demonstra que os respondentes preferem elaborar um orçamento que possa ser atingido, o que pode implicar criação de folga orçamentária, seja pela superestimação de custos/despesas ou subestimação de receitas (BOURGEOIS; SINGH, 1983). Na dimensão "Atitude relativa à relevância de atingir o orçamento para avaliação", a maioria concorda totalmente que se não realizar os valores orçados, o superior hierárquico faz questionamentos.

Sobre a dimensão "Propósito do orçamento", a maioria concorda que o orçamento é uma das ferramentas essenciais para a área de negócios, o que corrobora o exposto por Hansen, Otley e Van Der Stede (2003) e 
Frezatti et al. (2010), que o orçamento é considerado o principal artefato do sistema de controle gerencial. Na dimensão "Importância do orçamento", a maior concordância foi observada na questão que assevera que os critérios estabelecidos na construção do plano orçamentário influenciam o aumento de produtividade, o que pode decorrer de um maior compromisso dos gestores com a estratégia deliberada (FREZATTI et al., 2010).

De modo geral, depreende-se com base nas indicações dos respondentes para as cinco alternativas da escala Likert em cada uma das questões que pretendiam analisar a propensão dos gestores de criar folga na gestão do orçamento, que há fortes indícios de práticas de folga orçamentária na empresa pesquisada. Esses resultados coadunam com os resultados da pesquisa de Onsi (1973), realizada com 32 gerentes de cinco multinacionais norte-americanas com estrutura divisional, em que os entrevistados afirmaram introduzir folga no orçamento, principalmente quando ele é a base da avaliação de desempenho.

As medidas descritivas de cada uma das dimensões do levantamento são apresentadas na Tabela 3. O Teste T-Student para a comparação de duas médias populacionais foi realizado levando-se em consideração a média da avaliação interna dos respondentes, a qual foi 4,30 pontos, ou seja, formaram-se dois grupos, um com nota acima de 4,30 $(>=4,30)$ e outro abaixo de 4,30 $(<4,30)$. O primeiro foi o grupo com nota alta, ou seja, excelente desempenho no alcance das metas do orçamento; e o segundo com nota baixa, ou seja, desempenho inferior no alcance das metas orçamentárias.

Tabela 3: Medidas descritivas de cada uma das dimensões do levantamento

\begin{tabular}{|c|c|c|c|c|c|}
\hline Dimensões do levantamento & $\begin{array}{l}\text { Avaliação } \\
\text { interna }\end{array}$ & Casos & Média & $\begin{array}{l}\text { Desvio } \\
\text { padrão }\end{array}$ & Desvio do erro médio \\
\hline \multirow{2}{*}{$\begin{array}{l}\text { Folga do responsável da área na elaboração } \\
\text { do orçamento }\end{array}$} & $>=4,30$ & 19 & 2,2632 & ,87191 & ,20003 \\
\hline & $<4,30$ & 13 & 2,5385 & 1,05003 & ,29123 \\
\hline \multirow{2}{*}{ Manipulação do orçamento } & $>=4,30$ & 19 & 4,0526 &, 70504 & ,16175 \\
\hline & $<4,30$ & 13 & 4,0769 &, 75955 &, 21066 \\
\hline \multirow{2}{*}{ Institucionalização de folgas } & $>=4,30$ & 19 & 2,9474 & 1,07877 & ,24749 \\
\hline & $<4,30$ & 13 & 3,1538 & 1,14354 & ,31716 \\
\hline \multirow{2}{*}{ Detecção de folgas } & $>=4,30$ & 19 & 4,1053 &, 80930 &, 18567 \\
\hline & $<4,30$ & 13 & 4,3077 &, 75107 & ,20831 \\
\hline \multirow{2}{*}{$\begin{array}{l}\text { Atitude em relação ao sistema de controle } \\
\text { da alta administração }\end{array}$} & $>=4,30$ & 19 & 3,6316 &, 76089 &, 17456 \\
\hline & $<4,30$ & 13 & 3,9231 & ,64051 & ,17765 \\
\hline \multirow{2}{*}{ Atitude em relação aos subordinados } & $>=4,30$ & 19 & 3,0000 & 1,00000 & ,22942 \\
\hline & $<4,30$ & 13 & 3,1538 & ,98710 & ,27377 \\
\hline \multirow{2}{*}{ Pressão } & $>=4,30$ & 19 & 4,2105 & ,91766 & ,21053 \\
\hline & $<4,30$ & 13 & 4,5385 &, 51887 & ,14391 \\
\hline \multirow{2}{*}{ Autonomia orçamentária } & $>=4,30$ & 19 & 2,0526 & 1,12909 & ,25903 \\
\hline & $<4,30$ & 13 & 2,5385 & 1,05003 & ,29123 \\
\hline \multirow{2}{*}{ Participação no orçamento } & $>=4,30$ & 19 & 3,4737 &, 77233 & ,17718 \\
\hline & $<4,30$ & 13 & 3,6154 & ,76795 & ,21299 \\
\hline \multirow{2}{*}{ Práticas de fiscalização do orçamento } & $>=4,30$ & 19 & 4,1579 & ,60214 &, 13814 \\
\hline & $<4,30$ & 13 & 4,2308 &, 72501 & ,20108 \\
\hline \multirow{2}{*}{ Atitude relativa aos critérios } & $>=4,30$ & 19 & 4,0526 &, 84811 &, 19457 \\
\hline & $<4,30$ & 13 & 4,0769 &, 86232 & ,23916 \\
\hline \multirow{2}{*}{$\begin{array}{l}\text { Atitude relativa à relevância de atingir o } \\
\text { orçamento para avaliação }\end{array}$} & $>=4,30$ & 19 & 4,4737 & 61178 & ,14035 \\
\hline & $<4,30$ & 13 & 4,6923 & ,48038 & ,13323 \\
\hline \multirow{2}{*}{ Propósito do orçamento } & $>=4,30$ & 19 & 4,0526 & ,91127 & ,20906 \\
\hline & $<4,30$ & 13 & 3,7692 & 1,09193 &, 30285 \\
\hline \multirow{2}{*}{ Importância do orçamento } & $>=4,30$ & 19 & 2,6316 & 68399 & ,15692 \\
\hline & $<4,30$ & 13 & 3,0769 & ,64051 &, 17765 \\
\hline
\end{tabular}


As médias dos respondentes para as dimensões que obtiveram médias baixas, ou seja, desempenho inferior no alcance das metas orçamentárias, foram os que reforçaram que: a) existe folga do responsável da área na elaboração do orçamento; b) demonstram serem mais propensos à manipulação e institucionalização de folgas no orçamento; c) concordam que a empresa tem detecção de folgas e respeito ao sistema de controle da alta administração; d) concordam com atitude mais rígida em relação aos subordinados; e) concordam com a pressão do processo orçamentário; f) entendem que tem mais autonomia orçamentária e participação no orçamento do que os respondentes com maior média nas dimensões pesquisadas.

$\mathrm{Na}$ percepção destes respondentes, as médias indicam que concordam que há práticas de fiscalização do orçamento e que preferem realizar um orçamento que possa ser mais facilmente atingido. Também as médias destes respondentes denotam mais atitude relativa à relevância de atingir o orçamento para avaliação, bem como para a importância do orçamento. A única dimensão em que as médias foram menores para os respondentes com nota mais baixa foi a dimensão referente ao "Propósito do orçamento", o que não surpreende, já que estão mais propensos a criar folga em seus orçamentos.

Ressalta-se, no entanto, que a folga orçamentária não necessariamente deve ser vista sob uma conotação negativa. De acordo com Cyert e March (1963) e Bourgeois (1981), a folga possibilita que os gestores façam experiências de forma mais segura, com novas estratégias e projetos inovadores. Assim, a organização pode competir no seu ambiente de modo mais ousado, o que possivelmente seria inibido em um ambiente com recursos limitados. Por outro lado, o excesso de folga pode configurar-se como uma forma de desperdício e de gastos que afetam negativamente o desempenho da empresa (NOHRIA; GULATI, 1997; LIMA, 2008; FACÓ, 2009).

\section{Conclusões}

Esta pesquisa objetivou verificar em que medida a remuneração variável é um incentivo para os gestores criarem folga no processo orçamentário. Os resultados da pesquisa demonstraram que, em média, os gestores pesquisados, especialmente os que tiveram desempenho inferior no alcance das metas, têm maior propensão para criar folga em seus orçamentos, e que a remuneração variável atrelada às metas orçamentárias pode contribuir para a prática da criação de folga no processo orçamentário.

Os resultados mostram também que as práticas de fiscalização do orçamento e detecção de folga inibem de certa forma a propensão dos gestores de criar folga. No que concerne ao sistema de controle do orçamento, os respondentes concordam que o superior hierárquico exerce pressão para que as metas das áreas de negócios aconteçam.

O fato de a empresa ter remuneração variável atrelada às metas do orçamento contribui para a formação de folga, conforme constatado nas respostas sobre a dimensão "Atitude relativa à importância de atingir o orçamento para avaliação". A maioria dos respondentes concordou totalmente que serão avaliados pelo seu superior hierárquico em relação ao cumprimento das metas orçamentárias, o que pode favorecer a propensão para criar folga orçamentária por meio de superestimação de custos/despesas ou subestimação de receitas (BOURGEOIS; SINGH, 1983).

Conclui-se com base nos resultados da pesquisa que há indícios de propensão dos gestores entrevistados criar folga no processo orçamentário, especialmente no caso dos gestores com desempenho inferior no alcance das metas orçamentárias, já que a remuneração variável está atrelada ao desempenho. Esses resultados coadunam com os da pesquisa de Onsi (1973), realizada em cinco multinacionais norte-americanas com estrutura divisional.

Como principal limitação do estudo tem-se que os resultados da pesquisa não podem ser generalizados, ou seja, restringem-se à empresa pesquisada. Portanto, esse aspecto pode despertar interesse de outros pesquisadores para reaplicar a pesquisa em outras organizações e assim comparar os resultados encontrados. Outro aspecto que requer parcimônia na interpretação dos resultados diz respeito ao constructo e ao instrumento de pesquisa utilizados para captar a presença ou não de folga orçamentária na empresa objeto de estudo. 


\section{Referências}

ANTHONY, R. N.; GOVINDARAJAN, V. Sistemas de controle gerencial. São Paulo: Atlas, 1998.

BEUREN, I. M.; SILVA, T. P. Participação no orçamento empresarial como forma de valorização das pessoas: análise na perspectiva da justiça organizacional. Revista Organizações em Contexto (Online), v. 10, n. 19, p. 71-101, 2014.

BEUREN, I. M.; STAROSKY FILHO, L.; KRESPI, N. T. Folga organizacional versus desempenho financeiro: um estudo nas empresas da BM\&FBovespa. Contaduria y Administracion, v. 59, n. 2, p. 145177, 2014.

BOURGEOIS, L. J. On the measurement of organizational slack. Academy of Management Review, v. 6, p. 29-39, 1981.

BOURGEOIS, L. J.; SINGH, J. V. Organizational slack and political behavior among top management teams. Academy of Management Proceedings, p. 43-48, 1983.

BROMILEY, Philip. Testing a causal model or corporate risk taking and performance. The Academy of Management Journal. v. 34, n. 1, p.37-59, 1991.

CORRÊA, W. E. Participação nos lucros ou resultados: uma metodologia inteligente aplicável a todas as empresas. São Paulo: Atlas, 1999.

CYERT, R. M.; MARCH, J. G. A behavioral theory of the firm. Englewood Cliffs, NJ: Prentice Hall, 1963.

DAVILA, A.; WOUTERS, M. Managing budget emphasis through the explicit design of conditional budgetary slack. Accounting, Organization and Society, v. 30, n. 6, p. 587-608, 2005.

ESPEJO, M. M. S. B. Perfil dos atributos do sistema orçamentário sob a perspectiva contingencial: uma abordagem multivariada. 2008. 216f. Tese (Doutorado em Ciências Contábeis) - Universidade de São Paulo, São Paulo, Brasil, 2008.

FACÓ, J. F. B. Capacidade de inovação organizacional: uma análise aplicada à indústria de transformação paulista. 2009. 215 f. Tese (Doutorado em Administração de Empresas) Fundação Getúlio Vargas, São Paulo, Brasil, 2009.
FISCHER, A. L. Um resgate conceitual e histórico dos modelos de gestão de pessoas. In: FLEURY, M. T. L.; SAMPAIO, J. R. (orgs.). As pessoas na organização. São Paulo: Gente, 2002.

FLECK, D. L.; SENDER, G. Folga organizacional em bancos brasileiros nos anos 1990. In: HILAL, A.; MACEDO-SOARES, T. (orgs.). Estudos em negócios II. Rio de Janeiro: Mauad, 2005.

FREZATTI, F. Orçamento empresarial: planejamento e controle gerencial. São Paulo: Atlas, 2006.

FREZATTI, F.; RELVAS, T.; JUNQUEIRA, E. R.; NASCIMENTO, A. R.; OYADOMARI, J. C. Críticas ao orçamento: problemas com o artefato ou a não utilização de uma abordagem abrangente de análise? Advances in Scientific and Applied Accounting, v. 3, n. 2, p. 190-216, 2010.

GIL, A. C. Métodos e técnicas de pesquisa social. 5. ed. São Paulo: Atlas, 1999.

HANSEN, S. C.; OTLEY, D. T.; VAN DER STEDE, W. A. Practice developments in budgeting: an overview and research perspective. Journal of Management Accounting Research, v. 15, n. 1, p. 95-116, 2003.

HAIR JR, J. F. Análise multivariada de dados. Traduzido por Adonai Schlup Sant'Anna e Anselmo Chaves Neto. 5. ed. Porto Alegre: Bookman, 2005.

INDJEJIKIAN, R. J.; MATEJKA, M. Organizational slack in decentralized firms: the role of business unit controllers. The Accounting Review, v. 81, n. 4, p. 849-872, 2006.

JENSEN, M. C.; MURPHY, K. J. Performance pay and top-management incentives. The Journal of Political Economy, v. 98, n. 2, p. 225-264, 1990.

JUNQUEIRA, E.; OYADOMARI, J. C. T.; MORAES, R. O. Reservas orçamentárias: um ensaio sobre os fatores que levam à sua constituição. ConTexto, v. 10, n. 17, p. 31-42, 2010.

KRAUTER, E.; SOUSA, A. F. Executive compensation and corporate financial performance: empirical evidences on Brazilian industrial companies. Journal of Modern Accounting and Auditing, v. 9, n. 5, p. 650-661, 2013.

LAVARDA, C. E. F; FANK, O. L. Relação da assimetria 
da informação, da participação orçamentária e do risco na criação da folga orçamentária. Contextus, v. 12, n. 1, p. 81-110, 2014.

LEITE, R. M.; SILVA, H. F. N.; CHEROBIM, A. P. M. S.; BUFREM, L. S. Orçamento empresarial: levantamento da produção científica no período de 1995 a 2006. Revista Contabilidade \& Finanças, USP, v. 19, n. 47, p. 56 - 72, 2008.

LIMA, A. F. Estudo da relação causal entre os níveis organizacionais de folga, o risco e o desempenho financeiro de empresas manufatureiras. 2008. 252f. Tese (Doutorado em Administração de Empresas) Universidade Presbiteriana Mackenzie, São Paulo, Brasil, 2008.

LUNKES, R. J. Manual do orçamento. São Paulo: Atlas, 2003.

MACHADO, D. G.; BEUREN, I. M. Política de remuneração de executivos: um estudo em empresas industriais brasileiras, estadunidenses e inglesas. Gestão \& Regionalidade, v. 30, n. 90, 2014.

MARQUART, A.; LUNKES, R. J.; ROSA, F. S. Um estudo sobre práticas de remuneração estratégica nas maiores empresas de Santa Catarina. Gestão e Sociedade (UFMG), v. 6, n. 2, p. 296-317, 2012.

MARTINS, G. A.; THEÓPHILO, C. R. Metodologia da investigação científica para ciências sociais aplicadas. São Paulo: Atlas, 2007.

MUSSA, A.; RÊGO, R. H. T.; SECURATO, J. R. O processo orçamentário e as imagens da organização. In: CONGRESSO USP DE CONTROLADORIA E CONTABILIDADE, 10., 2010, São Paulo. Anais... São Paulo: FEA/USP, 2010. CD-ROM.

NEELY, A.; SUTCLIFF, M. R.; HEYNS, H. R. Driving value through strategic planning and budgeting. New York: Accenture, 2001.

NOHRIA, N.; GULATI, R. What is the optimum amount of organizational slack? A study of the relationship between slack and innovation in multinational firms. European Management Journal, v. 15, n. 6, p. 603-611, 1997.

ODELIUS, C. C.; SANTOS, A. R. Percepção de justiça organizacional de sistemas de remuneração em organizações públicas. Alcance (Univali), v. 15, n. 2, p. 226-242, 2008.
OLIVEIRA, C. R.; LAVARDA, C. E. F.; PATON, C. Fatores determinantes da folga orçamentária associados ao ciclo de vida organizacional. In: SEMINÁRIOS EM ADMINISTRAÇÃO, 13., 2010, São Paulo. Anais... São Paulo: FEA/USP, 2010. CDROM.

ONSI, M. Factor analysis of behavioral variables affecting budgetary slack. The Accounting Review, v. 48 , n. 3 , p. $535-548,1973$.

QUINTAS, T. T.; BEUREN, I. M. Abordagens sobre folga organizacional nas pesquisas publicadas em periódicos internacionais: um ensaio teórico. Revista de Administração da UFSM, v. 4, n. 1, p. 53-72, 2011.

RICHARDSON, R. J. Pesquisa social: métodos e técnicas. 3. ed. São Paulo: Atlas, 1999.

SENDER, G. O papel da folga organizacional nas empresas: um estudo em bancos brasileiros. $226 \mathrm{f}$. 2004. Dissertação (Mestrado em Administração) Universidade Federal do Rio de Janeiro, Rio de Janeiro, Brasil, 2004.

SHARFMAN, M. P.; WOLF, G.; CHASE, R. B.; TANSIK, D. A. Antecedents of organizational slack. The Academy of Management Review, v. 13, n. 4, p. 601-614, 1988.

SOARES, J. P. R. F. A influência da orientação à geração de valor ao acionista nas práticas de gestão de pessoas. 113 f. 2006 . Dissertação (Mestrado em Engenharia) - Escola Politécnica da Universidade de São Paulo, São Paulo, Brasil, 2006.

TAN, J.; PENG, M. W. Organizational slack and firm performance during economic transitions: two studies from an emerging economy. The Strategic Management Journal. v. 24, n. 13, p. 1249-1263, 2003.

TRIVIÑOS, A. N. S. Introdução à pesquisa em ciências sociais: a pesquisa qualitativa em educação. São Paulo: Atlas, 1987.

YIN, R. K. Estudo de caso: planejamento e métodos. 2. ed. Porto Alegre: Bookman, 2004.

WOOD JUNIOR, T.; PICARELLI FILHO, V. Remuneração estratégica: nova vantagem competitiva. 2. ed. São Paulo: Atlas, 1999. 